\title{
Analisis Quality of Service Pada Jaringan Komputer
}

\author{
Ida Bagus Agung Eka Mandala Putra ${ }^{1}$, Made Sri Indradewi Adnyana ${ }^{2}$, Lie Jasa ${ }^{3}$
}

[Submission: 30-05-2020, Accepted: 05-032021]

\begin{abstract}
A digital era where technological developments are growing rapidly, making it easier to access information from various parts of the world. Internet with unlimited reach can connect all computers around the world making it easier for users to get information, communicate and forge partnerships. Computer networks are not new, it can be said that almost all organizations, agencies and digital agency companies use network connections to support management activities. The top priority in the organization in order to be widely connected to facilitate access to information. With a large number of users connected within an organization / agency, internet traffic is very dense. Therefore the importance of an administrator in the field of computer networks in bandwidth management. Kesato Digital Agency, companies in the IT field have 2 network topologies that connect 5 fields to support their company's activities. In this case the stakeholders intend to evaluate and measure the quality of network services applied to the company. So it is necessary to conduct a Quality of Service assessment on the computer network of the Digital Agency to determine the ability of the network connection to fulfill company activities. The results of the Quality of Service assessment at Kesato Digital Agency are in the satisfactory category, of course, there needs to be some improvement efforts to achieve maximum results in the very satisfying category.
\end{abstract}

Key words : Quality of Service, Kesato, Digital Agency, Bandwidth

Intisari- Suatu era digital dimana perkembangan teknologi tumbuh dengan pesat, menyebabkan kemudahan dalam mengakses informasi dari berbagai belahan dunia. Internet dengan jangkuan tanpa ada batas dapat menghubungkan seluruh komputer diseluruh dunia memudahkan pengguna dalam mendapatkan informasi, berkomunikasi dan menjalin kemitraan. Jaringan komputer bukan merupakan hal yang baru, dapat dikatakan hampir seluruh organisasi, instansi dan perusahaan digital agency mempergunakan jaringan koneksi dalam menunjang kegiatan manajemen. Kebutuhan tersebut menjadi prioritas utama dalam organisasi agar dapat terhubung secara luas untuk mempermudah dalam hal mengakses informasi. Dengan banyak jumlah pengguna yang terkoneksi didalam suatu organisasi/instansi menyebabkan traffic internet sangatlah padat. Oleh karena itu pentingnya seorang administrator dibidang jaringan komputer dalam pengelolaan bandwidth. Pada Kesato Digital Agency perusahaan dibidang IT

1, 2 Mahasiswa, Program Pasca Sarjana, Manajemen Sistem Informasi dan Komputer Fakultas Teknik Universitas Udayana, Jln. P.B. Sudirman, Denpasar, Bali 80232 INDONESIA (tlp: 0361-239599; e-mail: eka.mandala@student.unud.ac.id, indradewi.adnyana@student.unud.ac.id)

${ }^{3}$ Dosen, Program Pasca Sarjana, Magister Teknik Elektro Fakultas Teknik Universitas Udayana, Jln. P.B. Sudirman, Denpasar, Bali 80232 INDONESIA (telp: 0361-239599 e-mail : liejasa@unud.ac.id)

Ida Bagus Agung Eka Mandala Putra : Analisis Quality of Service ... terdapat 2 topologi jaringan yang menghubungkan 5 bidang untuk mendukung kegiatan perusahaannya. Dalam hal ini pemangku kepentingan bermaksud untuk mengevaluasi serta mengukur kualitas layanan jaringan yang diterapkan pada perusahaan. Sehingga itu perlu dilakukan penilaian Quality of Service pada jaringan komputer perusahaan Digital Agency untuk mengetahui kemampuan koneksi jaringan dalam memenuhi kegiatan perusahaan. Hasil penilaian Quality of Service pada Kesato Digital Agency dalam kategori memuaskan, tentunya perlu ada upaya perbaikan untuk mencapai hasil maksimal pada kategori sangat memuaskan.

Kata Kunci- Quality of Service, Kesato, Digital Agency, Bandwidth

\section{PENDAHULUAN}

Suatu era digital dimana perkembangan teknologi tumbuh dengan pesat, menyebabkan kemudahan dalam mengakses informasi dari berbagai belahan dunia. Internet dengan jangkauan tanpa ada batas dapat menghubungkan seluruh komputer dalam suatu koneksi yang memudahkan pengguna dalam mendapatkan informasi, berkomunikasi dan menjalin kemitraan. Sebagai contoh nilai positif dengan adanya jaringan internet didalam masa pendemi Covid-19 yang melanda Negara Kesatuan Republik Indonesia dengan koneksi internet memungkinkan warga untuk bekerja dari rumah (work from home), sekaligus dengan bekerja dari rumah kita berperan dalam memutus penyebaran virus corona tersebut. Sebagian masyarakat mungkin terasa asing dengan internet, namun manfaat dari internet dengan jaringan yang luas dapat memudahkan aktifitas kehidupan masyarakat.

Jaringan komputer bukan merupakan hal yang baru, dapat dikatakan hampir seluruh organisasi, instansi dan perusahaan digital agency mempergunakan jaringan koneksi dalam menunjang kegiatan manajemen. Kebutuhan tersebut menjadi prioritas utama dalam organisasi agar dapat terhubung secara luas untuk mempermudah dalam hal mengakses informasi. Dengan banyak jumlah pengguna yang terkoneksi didalam suatu organisasi/instansi menyebabkan traffic internet sangatlah padat. Oleh karena itu pentingnya seorang administrator dalam bidang jaringan melakukan upaya dalam pengelolaan bandwidth [1]. Pada Kesato Digital Agency yang merupakan unit bisnis yang bergerak dibidang pengembangan perangkat lunak tentunya menggunakan internet dalam menunjang kegiatan bisnis. Dalam hal ini pemangku kepentingan pada perusahaan ingin memberikan layanan koneksi jaringan yang baik untuk kegiatan manajemen yang maksimal. Mitigasi terhadap terjadinya masalah gangguan jaringan komputer pada saat traffic internet yang sangat padat mengakibatkan aktifitas perusahaan menjadi terhambat. Kebutuhan pengguna jaringan internet pada Kesato Digital Agency meliputi browsing, streaming, upload serta download menyebabkan penggunaan bandwidth menjadi besar, apabila 
tidak dikelola menyebabkan terjadinya masalah pada jaringan komputer [2].

Melihat hal tersebut seorang administrator jaringan perlu melaksanakan suatu mekanisme manajemen untuk mengatur penggunaan bandwith. Pengelolaan adalah suatu hal yang sangat penting pada jaringan komputer bertujuan dalam memberikan koneksi internet dengan baik pada setiap pengguna. Perlu dilaksanakan mekanisme evaluasi dan pengukuran untuk mengetahui kualitas dari penerapan suatu jaringan internet. Quality of Service atau yang biasa dikenal dengan QoS adalah teknologi yang diimplementasikan pada jaringan komputer dalam memberikan layanan dengan optimal dan merata kepada setiap pengguna jaringan komputer. QoS dapat memungkinkan seorang administrator jaringan komputer mampu menangani beraneka ragam dampak akibat dari terjadinya gangguan dalam lalu lintas arah paket dalam jaringan [3].

Oleh karena itu analisis quality of service pada jaringan komputer pada perusahaan sangat diperlukan untuk mengukur kualitas jaringan, memberikan layanan koneksi yang baik serta pengelolaan bandwidth yang merata. Dapat dikatakan bahwa setiap karyawan dimulai dari atasan sampai dengan bawahan membutuhkan jaringan komputer untuk bekerja. Sehingga perlu adanya upaya mengoptimalkan layanan jaringan agar memiliki kualitas dan kemampuan yang baik. Berdasarkan latar belakang permasalahan diatas, tujuan penelitian ini menganalisa quality of service jaringan komputer pada Kesato Digital Agency, untuk evaluasi dan menilai kualitas terhadap jaringan komputer pada perusahaan. Harapan dari pemangku kepentingan perusahaan dapat memberikan layanan jaringan dengan baik dan memuaskan kepada pengguna untuk mengoptimalkan proses kinerja manajemen.

\section{TinjauAn Pustaka}

\section{A. Jaringan Komputer}

Jaringan komputer merupakan gabungan dua atau lebih komputer yang terhubung satu dengan yang lainnya dalam melaksanakan komunikasi data mempergunakan protokol komunikasi dengan media komunikasi berupa kabel maupun nirkabel [4]. Sistem yang terdiri dari beberapa komputer didesain agar dapat berkomunikasi, melakukan akses terhadap informasi serta berbagi sumber daya [5]. Penerapan jaringan komputer terhadap suatu organisasi atau instansi dapat memberikan kemudahan dalam kinerja manajemen yang lebih efektif.

\section{B. Bandwidth}

Pada suatu jaringan internet tentunya ketersediaan bandwidth sangatlah penting. Bandwidth merupakan suatu pengukuran dari banyaknya informasi baik aliran data digital maupun data analog. Bandwidth saat ini lebih banyak dilakukan untuk mengukur aliran data digital dengan satuan yang dimiliki yaitu bits per second atau bps. Bit atau disebut binery digit merupakan basis angka terdiri atas angka 0 dengan 1. Satuan tersebut mendeskripsikan jumlah bit angka 0 dengan 1yang mampu mengalir dari suatu tempat ke tempat lainya pada setiap detik yang melalui satu media[6].

\section{Manajemen Bandwidth}

Manajemen dalam bahasa inggris to manage merupakan suatu kegiatan mengelola. Selanjutnya bandwidth merupakan lebar data yang mampu diproses dalam komunikasi data dengan jaringan komputer dihitung melalui besaran bit/second. Manajemen bandwidth merupakan suatu kegiatan yang mengatur supaya data yang terlewat dapat sesuai dengan kapasitas maksimal atau bandwidth dalam suatu jaringan komputer yang terhubung dengan internet untuk kualitas jaringan terjamin [7].

\section{Quality of Service}

Quality of Service atau QoS adalah metode penilaian berkaitan dengan seberapa baik suatu jaringan komputer dan merupakan usaha dalam menentukan karakteristik beserta sifat dari suatu layanan. QoS dipergunakan dalam menilai kumpulan artribut kinerja yang sudah dispesifikasikan serta diasosiasikan pada suatu layanan. Mengacu pada kapabilitas jaringan dalam memfasilitasi layanan lebih baik dalam traffic jaringan komputer tertentu dengan teknologi yang berbeda [8]. Adapun persentase penilaian dari Quality of Service sebagai berikut.

TABEL I

PERSENTASE PENILAIAN QoS

\begin{tabular}{|c|c|l|}
\hline $\begin{array}{c}\text { Kategori } \\
\text { Penilaian }\end{array}$ & Persentase & \multicolumn{1}{|c|}{ Indeks } \\
\hline $3.8-4$ & $95-100$ & Sangat Memuaskan \\
\hline $3-3.79$ & $75-94.75$ & Memuaskan \\
\hline $2-2.99$ & $50-74.75$ & $\begin{array}{l}\text { Kurang } \\
\text { Memuaskan }\end{array}$ \\
\hline $1-1.99$ & $25-49.75$ & Tidak Memuaskan \\
\hline
\end{tabular}

Adapun parameter-parameter yang dipergunakan dalam menentukan QoS antara lain Throughput, Delay, Jitter dan Packet Loss [1]. Kemudian penilaian parameter QoS berdasarkan Telecommunications and Internet Protocol Harmonization Over Networks (TIPHON), merupakan suatu standar yang digunakan sebagai penilaian QoS dikeluarkan badan standar European Telecommunications Standards Institute (ETSI) [9]. Adapun penjelasan parameter-parameter Quality of Service sebagai berikut.

\section{Throughput}

Throughput adalah bandwidth yang sebenarnya diukur pada ukuran waktu tertentu dalam mentransmisikan file [1]. Throughput juga menggambarkan total kedatangan paket yang secara sukses dapat diamati dengan orientasi selama interval waktu tertentu dan dibagi dengan durasi interval waktu tersebut [1].

TABEL III

KATEGORI THROUGHPUT

\begin{tabular}{|c|c|c|}
\hline $\begin{array}{c}\text { Kategori } \\
\text { Throughput }\end{array}$ & Throughput & Indeks \\
\hline Sangat Bagus & $>2.1 \mathrm{Mbps}$ & 4 \\
\hline
\end{tabular}




\begin{tabular}{|l|c|c|}
\hline Baik & $1200 \mathrm{kbps}-2.1 \mathrm{Mbps}$ & 3 \\
\hline Kukup & $700-1200 \mathrm{kbps}$ & 2 \\
\hline Kurang Baik & $338-700 \mathrm{kbps}$ & 1 \\
\hline Buruk & $0-338 \mathrm{kbps}$ & 0 \\
\hline
\end{tabular}

Dengan rumus pengukuran sebagai berikut

$$
\text { Throughput }=\frac{\text { Jumlah data yang dikirim }(\mathrm{kb})}{\text { Waktu Peringiriman data }(\mathrm{s})}
$$

\section{Delay}

Delay adalah parameter QoS menunjukan total waktu yang dibutuhkan paket dalam menempuh jarak dari source ke tujuan. Hal-hal yang dapat mempengaruhi delay yaitu perangkat keras, jarak dan congestion. Standar delay berdasarkan versi TIPHON ditunjukan pada Tabel 3 sebagai berikut. [10].

TABEL IIIII

KATEGORI DELAY

\begin{tabular}{|l|c|c|}
\hline $\begin{array}{c}\text { Kategory } \\
\text { Delay }\end{array}$ & $\begin{array}{c}\text { Besar } \\
\text { Delay }\end{array}$ & Indeks \\
\hline Sangat Bagus & $<150 \mathrm{~ms}$ & 4 \\
\hline Bagus & $150 \mathrm{~ms}-300 \mathrm{~ms}$ & 3 \\
\hline Sedang & $300 \mathrm{~ms}-450 \mathrm{~ms}$ & 2 \\
\hline Tidak Bagus & $>450$ & 1 \\
\hline
\end{tabular}

Dengan rumus pengukuran

\section{Jitter}

$$
\text { Rata }- \text { Rata Delay }=\frac{\text { Jumlah Delay }}{\text { Jumlah Paket Diterima }}
$$

Jitter ataupun variasi delay berkaitan dengan latency, yang menerangkan banyaknya variasi delay dalam transmisi data pada jaringan. Delay antrian dalam router serta switch menghasilkan jitter. Hal tersebut dihasilkan oleh variasivariasi waktu mengolah data, panjang antrian beserta waktu pengimpunan ulang terhadap paket pada akhir perjalanan jitter. Kategori penurunan kinerja jaringan menurut nilai peak jitter sebagai berikut [11].

TABEL IVY

KATEGORI JITTER

\begin{tabular}{|l|c|c|}
\hline \multicolumn{1}{|c|}{$\begin{array}{c}\text { Kategori } \\
\text { Jitter }\end{array}$} & Jitter & Indeks \\
\hline Sangat Bagus & $0 \mathrm{~ms}$ & 4 \\
\hline Bagus & $0 \mathrm{~ms}-75 \mathrm{~ms}$ & 3 \\
\hline Sedang & $75 \mathrm{~ms}-125 \mathrm{~ms}$ & 2 \\
\hline Tidak Bagus & $125 \mathrm{~ms}-225 \mathrm{~ms}$ & 1 \\
\hline
\end{tabular}

Dengan rumus pengukuran sebagai berikut

$$
\text { Jitter }=\frac{\text { Jumlah Variasi Delay }}{\text { Jumlah Paket Diterima }}
$$

\section{Packet Loss}

Ida Bagus Agung Eka Mandala Putra : Analisis Quality of Service ...
Packet Loss adalah parameter yang mendeskripsikan suatu keadaan dimana total paket yang hilang, biasa terjadi lantaran collision serta congestion dalam jaringan. Selanjutnya hal tersebut berpengaruh pada seluruh aplikasi sebab retransmisi tentu mengurangi efisiensi pada jaringan dengan keseluruhan. Walaupun mempunyai jumlah bandwidth yang cukup tersedia pada aplikasi-aplikasi tersebut. Berikut merupakan kategori packet loss menurut versi TIPHON [12].

TABEL V

KATEGORI PACKET LOSS

\begin{tabular}{|l|c|c|}
\hline \multicolumn{1}{|c|}{ Kategori } & Packet Loss & Indeks \\
\hline Sangat Bagus & $0 \%$ & 4 \\
\hline Bagus & $3 \%$ & 3 \\
\hline Sedang & $15 \%$ & 2 \\
\hline Tidak Bagus & $25 \%$ & 1 \\
\hline
\end{tabular}

Dengan rumus pengukuran nilai packet loss dengan menggunakan rumus persamaan sebagai berikut.

$$
\text { Packet Loss }=\frac{\text { Paket Data di Kirim-Paket Data di Terima }}{\text { Paket Data di Kirim }}
$$

\section{Metodologi Penelitian}

Penelitian ini dilakukan untuk mengukur quality of service pada jaringan komputer Kesato Digital Agency untuk mengetahui kualitas jaringan komputer yang diterapkan.

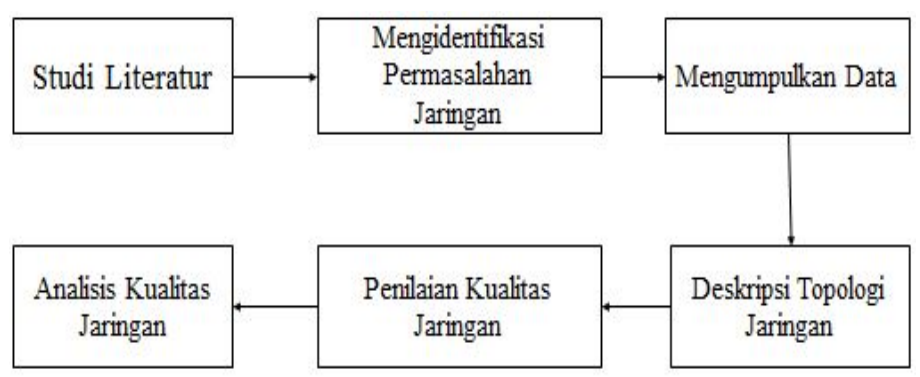

Gambar 1. Metodologi Penelitian

Tahap pertama dalam penelitian ini mengumpulkan studi literature yang berhubungan dengan penilaian kualitas jaringan, untuk mengetahui mekanisme penerapan metode tersebut. Kemudian tahap kedua mengidentifikasi atas permasalahan jaringan yang terdapat pada objek penelitian. Tahap berikutnya mengumpulkan data yang berkaitan dengan penelitian dengan observasi dan wawancara terhadap administrator jaringan komputer Kesato Digital Agency. Selanjutnya mendeskripsikan topologi jaringan yang terdapat pada objek penelitian. Kemudian tahap kelima mengamati paket data pada jaringan komputer dengan menggunakan aplikasi wireshark dan menilai kualitas jaringan dengan parameter QoS. Proses terakhir menganalisa kualitas jaringan untuk memberikan evaluasi terhadap pengelolaan jaringan komputer pada Kesato Digital Agency. 
A. Topologi Jaringan Kesato Digital Agency

Pada Gambar 2 dijelaskan topologi jaringan pada Kesato

Digital Agency dengan menggunakan dua topologi yaitu topologi bus dan topologi star.

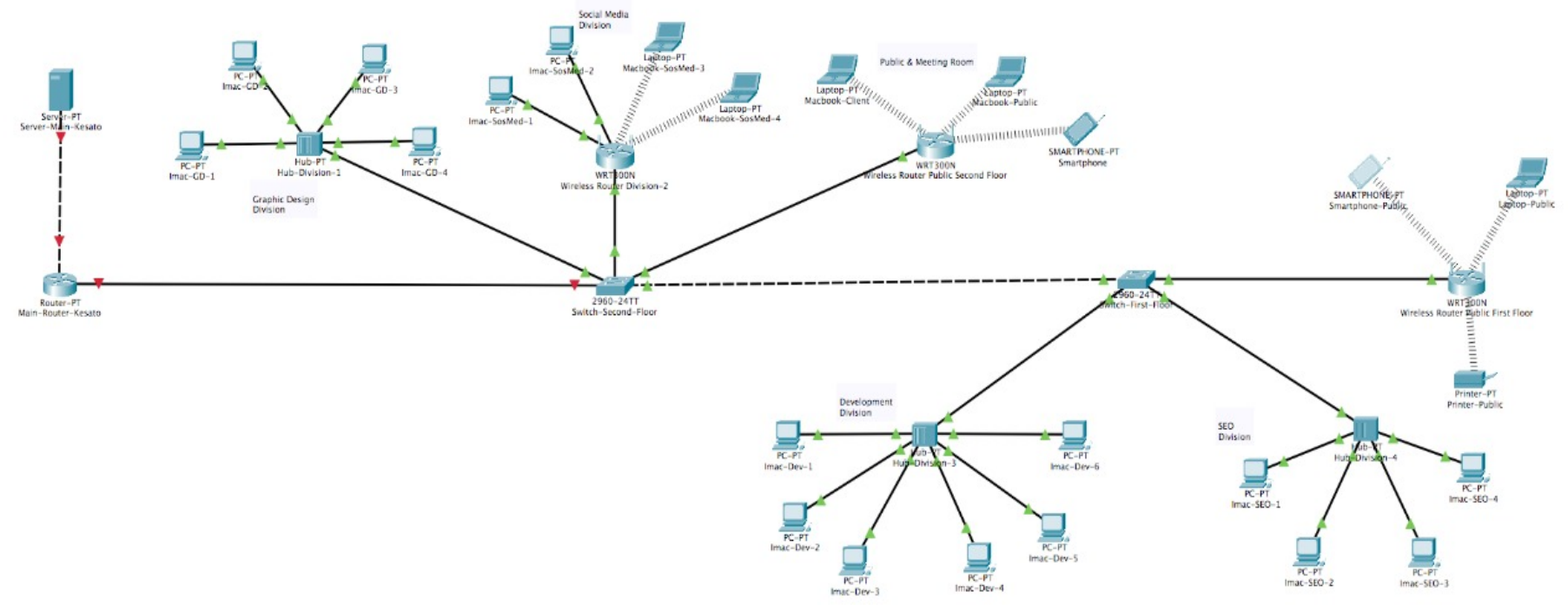

Gambar 2 Topologi Jaringan Komputer Kesato Digital Agency

Selanjutnya mengumpulkan data jaringan pada setiap

Pada Kesato Digital Agency menerapkan dua topologi jaringan untuk dapat mengubungkan empat divisi yaitu Divisi Development, Divisi Search Engine Optimize, Divisi Design Graphic dan Divisi Digital Marketing. Kesato Digital Agency pada saat ini memiliki jumlah bandwidth sebesar $200 \mathrm{Mbps}$ dengan mempergunakan 1 Internet Sevice Provider. Jumlah bandwidth tersebut dibagikan kepada empat divisi secara adil dan merata.

\section{HASIL DAN PEMBAHASAN}

Dalam penelitian ini, penulis mempergunakan aplikasi wireshark merupakan suatu perangkat lunak sniffer freeware untuk melihat suatu jaringan ethernet atau non-ethernet [8]. Pada Gambar 3 diperlihatkan grafik mengenai paket yang dikirim dan diterima pada jaringan komputer dalam 1 seconds.

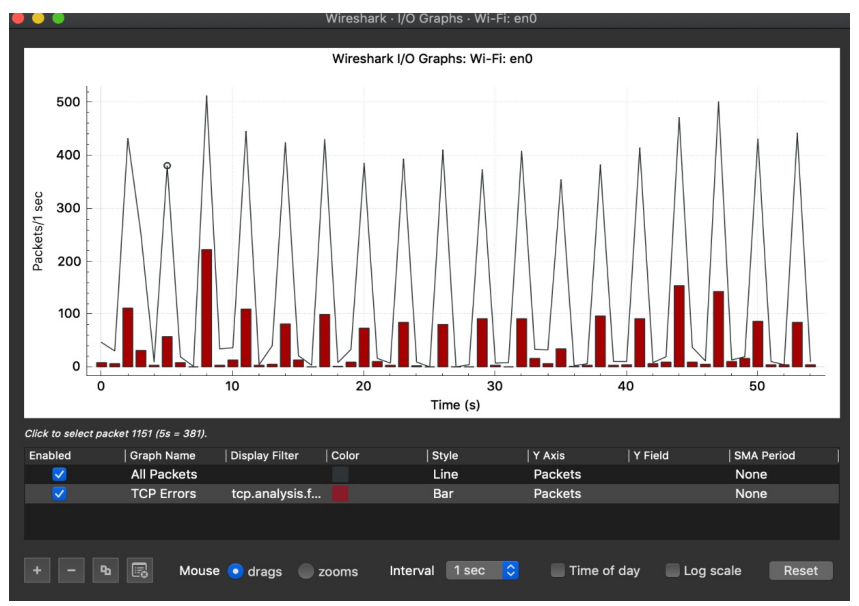

Gambar 3. Grafik Jaringan divisi yang ada pada Kesato Digital Agency. Proses tersebut dilakukan pada jam operasional kantor pada pukul 08.0017.00 wita serta pada jam waktu pulang kantor pukul 17.0022.00 wita selama lima hari. Pengukuran dilakukan pada sisi client dalam memeriksa jaringan pada setiap divisi. Indeks rata-rata yang terdapat pada setiap divisi Kesato Digital Agency ditunjukan pada Tabel 6 sebagai berikut.

Menurut hasil indeks rata-rata jaringan pada Kesato Digital Agency diatas diperoleh hasil penilaian berdasarkan parameter quality of service sebagai berikut.

\section{Throughput}

Berdasarkan hasil pengamatan jaringan pada waktu pagi hari pukul 08.00-12.00 wita, waktu siang hari pukul 13.0017.00 wita dan waktu malam hari pukul 18.00-22.00 wita. Adapun hasil ini menunjukan dari pengukuran throughput pada setiap divisi menurut versi TIPHON sebagai berikut [13].

$\mathrm{RTT}=(\mathrm{Th} 1+\mathrm{Th} 2) / 2$

Rumus:

- $\quad$ Th1 = Throughput Jam Kantor

- $\quad$ Th2 = Throughput Jam Pulang Kantor

- $\quad$ RTT = Rata-Rata Throughput

Rata-rata throughput Graphic Design Division adalah $\mathrm{RTT}=(53,14 \mathrm{kbps}+397,89 \mathrm{kbps}) / 2=252,085 \mathrm{kbps}$. 
TABEL VI

INDEKS RATA-RATA JARINGAN PADA KeSATO DIGITAL AGENCY

\begin{tabular}{|c|c|c|c|c|c|c|c|c|c|}
\hline \multirow{2}{*}{ No } & Pengukuran & \multicolumn{4}{|c|}{ Parameter QoS Jam Kantor } & \multicolumn{3}{|c|}{ Parameter QoS Pulang Kantor } \\
\cline { 3 - 10 } & & $\begin{array}{c}\text { Packet } \\
\text { Loss }(\%)\end{array}$ & $\begin{array}{c}\text { Delay } \\
(\mathbf{m s})\end{array}$ & $\begin{array}{c}\text { Jitter } \\
(\mathbf{m s})\end{array}$ & $\begin{array}{c}\text { Troughput } \\
(\boldsymbol{k b p s})\end{array}$ & $\begin{array}{c}\text { Packet } \\
\text { Loss }(\%)\end{array}$ & $\begin{array}{c}\text { Delay } \\
(\mathbf{m s})\end{array}$ & $\begin{array}{c}\text { Jitter } \\
(\mathbf{m s})\end{array}$ & $\begin{array}{c}\text { Troughput } \\
(\boldsymbol{k b p s})\end{array}$ \\
\hline 1 & Graphic Design Division & $1,5 \%$ & $2,18 \mathrm{~ms}$ & $11,37 \mathrm{~ms}$ & $53,14 \mathrm{kbps}$ & $7 \%$ & $0,52 \mathrm{~ms}$ & $0,13 \mathrm{~ms}$ & $397,89 \mathrm{kbps}$ \\
\hline 2 & Social Media Division & $0,03 \%$ & $1 \mathrm{~ms}$ & $2,4 \mathrm{~ms}$ & $445,94 \mathrm{kbps}$ & $0,46 \%$ & $2,87 \mathrm{~ms}$ & $2,87 \mathrm{~ms}$ & $288,88 \mathrm{kbps}$ \\
\hline 3 & Public \& Meeting Room & $0,8 \%$ & $2,45 \mathrm{~ms}$ & $1,74 \mathrm{~ms}$ & $442,82 \mathrm{kbps}$ & $0,25 \%$ & $2,23 \mathrm{~ms}$ & $2,05 \mathrm{~ms}$ & $352,71 \mathrm{kbps}$ \\
\hline 4 & SEO Division & $1,5 \%$ & $1 \mathrm{~ms}$ & $1 \mathrm{~ms}$ & $734,51 \mathrm{kbps}$ & $0,46 \%$ & $2,87 \mathrm{~ms}$ & $2,87 \mathrm{~ms}$ & $288,88 \mathrm{kbps}$ \\
\hline 5 & Development division & $0,3 \%$ & $2,17 \mathrm{~ms}$ & $185,47 \mathrm{~ms}$ & $432,83 \mathrm{kbps}$ & $0,04 \%$ & $5,44 \mathrm{~ms}$ & $5,46 \mathrm{~ms}$ & $143,87 \mathrm{kbps}$ \\
\hline
\end{tabular}

TABEL VII

PENGUKURAN THROUGHPUT

\begin{tabular}{|c|c|c|c|c|}
\hline \multirow{2}{*}{ No } & \multirow{2}{*}{ Divisi } & \multirow{2}{*}{$\begin{array}{c}\text { Rata-Rata } \\
\text { Throughput } \\
\text { (kbps) }\end{array}$} & \multicolumn{2}{|c|}{ Keterangan } \\
\hline & & & Indeks & Kategori \\
\hline 1 & $\begin{array}{l}\text { Graphic Design } \\
\text { Division }\end{array}$ & $252,085 \mathrm{kbps}$ & 0 & Buruk \\
\hline 2 & $\begin{array}{l}\text { Social Media } \\
\text { Division }\end{array}$ & $590,38 \mathrm{kbps}$ & 1 & $\begin{array}{c}\text { Kurang } \\
\text { Baik }\end{array}$ \\
\hline 3 & $\begin{array}{l}\text { Public \& Meeting } \\
\text { Room }\end{array}$ & $619,175 \mathrm{kbps}$ & 1 & $\begin{array}{c}\text { Kurang } \\
\text { Baik }\end{array}$ \\
\hline 4 & SEO Division & $878,95 \mathrm{kbps}$ & 2 & Cukup \\
\hline 5 & $\begin{array}{l}\text { Development } \\
\text { Division }\end{array}$ & $504,765 \mathrm{kbps}$ & 1 & $\begin{array}{c}\text { Kurang } \\
\text { Baik }\end{array}$ \\
\hline
\end{tabular}

Pada tabel diatas di tunjukan pada divisi Graphic Design Division mendapatkan indeks dengan nilai 0 dengan kategori buruk. Sedangkan pada divisi Sosial Media Divison, Public \& Meeting Room dan Development Division mendapatkan indeks 1 yang dengan kategori kurang baik. Kemudian pada divisi SEO Division mendapatkan indeks 2 dengan kategori cukup. Perlu adanya evaluasi terhadap manajemen bandwith pada setiap divisi-divisi tersebut oleh administrator jaringan.

\section{Packet Loss}

Menurut hasil pengamatan jaringan pada waktu pagi hari pukul 08.00-12.00 wita, waktu siang hari pukul 13.00-17.00 wita dan waktu malam hari pukul 18.00-22.00 wita. Hasil ini menunjukan hasil dari pengukuran packet loss pada setiap divisi dapat dilihat sebagai berikut [14].

RTPL $=(\mathrm{Pl} 1+\mathrm{Pl} 2) / 2$

Rumus:

- $\quad$ P11 = Packet Loss Jam Kantor

- $\quad \mathrm{Pl} 2=$ Packet Loss Jam Pulang Kantor

- $\quad$ RTPL = Rata-Rata Packet Loss

Rata-rata packet loss Graphic Design Division adalah RTPL $=(1,5 \%+7 \%) / 2=5 \%$.
TABEL VIII

PENGUKURAN PACKET LOSS

\begin{tabular}{|c|c|c|c|c|}
\hline \multirow[b]{2}{*}{ No } & \multirow[b]{2}{*}{ Divisi } & \multirow{2}{*}{$\begin{array}{c}\text { Rata-Rata } \\
\text { Packet } \\
\text { Loss }(\%)\end{array}$} & \multicolumn{2}{|c|}{ Keterangan } \\
\hline & & & Indeks & Kategori \\
\hline 1 & $\begin{array}{l}\text { Graphic Design } \\
\text { Division }\end{array}$ & $5 \%$ & 3 & Bagus \\
\hline 2 & $\begin{array}{l}\text { Social Media } \\
\text { Division } \\
\end{array}$ & $0,26 \%$ & 4 & $\begin{array}{l}\text { Sangat } \\
\text { Bagus }\end{array}$ \\
\hline 3 & $\begin{array}{l}\text { Public \& Meeting } \\
\text { Room }\end{array}$ & $0,92 \%$ & 4 & $\begin{array}{l}\text { Sangat } \\
\text { Bagus }\end{array}$ \\
\hline 4 & SEO Division & $1,73 \%$ & 4 & $\begin{array}{l}\text { Sangat } \\
\text { Bagus }\end{array}$ \\
\hline 5 & $\begin{array}{l}\text { Development } \\
\text { Division }\end{array}$ & $0,32 \%$ & 4 & $\begin{array}{l}\text { Sangat } \\
\text { Bagus }\end{array}$ \\
\hline
\end{tabular}

Dalam tabel packet loss diatas menunjukan Graphic Design Division mendapatkan nilai indeks 3 dengan kategori bagus. Adapun empat divisi lainnya meliputi Social Media Division, Public \& Meeting Room, SEO Division, Development Division mendapatkan nilai indeks 4 dengan kategori sangat bagus. Berdasarkan hasil penilaian diatas disimpulkan paket yang hilang dalam pengiriman data pada jaringan komputer tidak terlalu besar.

\section{Delay}

Berdasarkan hasil pengamatan jaringan yang dilakukan pada waktu pagi hari pukul 08.00-12.00 wita, pada waktu siang hari pukul 13.00-17.00 wita dan waktu malam hari pukul 18.00-22.00. Hasil ini menunjukan hasl pengukuran delay menurut versi TIPHON pada setiap divisi sebagai berikut [15].

$\mathrm{RTD}=(\mathrm{D} 1+\mathrm{D} 2) / 2$

Rumus:

- $\quad$ D1 = Delay Jam Kantor $\mid$ D2 = Delay Jam Pulang

- $\mathrm{RTD}=$ Rata-Rata Delay

Rata-rata delay Graphic Design Division adalah $\mathrm{RTD}=(2,18 \mathrm{~ms}+0,52 \mathrm{~ms}) / 2=2,44 \mathrm{~ms}$. 
TABEL IX

PENGUKURAN DELAY

\begin{tabular}{|l|l|l|l|l|}
\hline \multirow{2}{*}{ No } & \multicolumn{1}{|c|}{ Divisi } & $\begin{array}{c}\text { Rata-Rata } \\
\text { Delay }(\mathbf{m s})\end{array}$ & \multicolumn{2}{|c|}{ Keterangan } \\
\cline { 4 - 5 } 1 & $\begin{array}{l}\text { Graphic Design } \\
\text { Division }\end{array}$ & $2,44 \mathrm{~ms}$ & 4 & Kategori \\
\hline 2 & $\begin{array}{l}\text { Social Media } \\
\text { Division }\end{array}$ & $2,43 \mathrm{~ms}$ & 4 & Sangat Baik \\
\hline 3 & $\begin{array}{l}\text { Public \& } \\
\text { Meeting Room }\end{array}$ & $3,56 \mathrm{~ms}$ & 4 & Sangat Baik \\
\hline 4 & SEO Division & $2,43 \mathrm{~ms}$ & 4 & Sangat Baik \\
\hline 5 & $\begin{array}{l}\text { Development } \\
\text { Division }\end{array}$ & $4,89 \mathrm{~ms}$ & 4 & Sangat Baik \\
\hline
\end{tabular}

Pada tabel hasil penilaian delay diatas menunjukan pada lima divisi meliputi Graphic Design Division, Social Media Division, Public \& Meeting Room, SEO Division, dan Development Division mendapatkan nilai indeks 4 dengan kategori sangat baik. Hal diatas dapat disimpulkan bahwa pengiriman paket data pada jaringan komputer sangat baik.

\section{Jitter}

Menurut hasil pengamatan jaringan yang dilakukan pada waktu pagi hari pukul 08.00-12.00 wita, pada waktu siang hari pukul 13.00-17.00 wita dan waktu malam hari pukul 18.00-22.00 wita. Menunjukan hasil pengukuran jitter pada setiap divisi berdasarkan standar TIPHON sebagai berikut [16].

$\mathrm{RTJ}=(\mathrm{J} 1+\mathrm{J} 2) / 2$

Rumus:

- $\quad \mathrm{J} 1=$ Jitter Jam Kantor

- $\quad \mathrm{J} 2$ = Jitter Jam Pulang Kantor

- $\quad$ RTJ = Rata-Rata Jitter

Rata-rata jitter Graphic Design Division adalah $\mathrm{RTJ}=(11,37 \mathrm{~ms}+0,13 \mathrm{~ms}) / 2=252,085 \mathrm{kbps}$.

TABEL $X$

PENGUKURAN JITTER

\begin{tabular}{|c|c|c|c|c|}
\hline \multirow{2}{*}{ No } & \multirow{2}{*}{ Divisi } & \multirow{2}{*}{$\begin{array}{l}\text { Rata-Rata } \\
\text { Jitter }(\mathrm{ms})\end{array}$} & \multicolumn{2}{|c|}{ Keterangan } \\
\hline & & & Indeks & Kategori \\
\hline 1 & $\begin{array}{l}\text { Graphic Design } \\
\text { Division }\end{array}$ & $11,43 \mathrm{~ms}$ & 3 & Bagus \\
\hline 2 & $\begin{array}{l}\text { Social Media } \\
\text { Division }\end{array}$ & $3,83 \mathrm{~ms}$ & 3 & Bagus \\
\hline 3 & $\begin{array}{l}\text { Public \& Meeting } \\
\text { Room }\end{array}$ & $2,76 \mathrm{~ms}$ & 3 & Bagus \\
\hline 4 & SEO Division & $2,43 \mathrm{~ms}$ & 3 & Bagus \\
\hline 5 & $\begin{array}{l}\text { Development } \\
\text { Division }\end{array}$ & $188,2 \mathrm{~ms}$ & 1 & $\begin{array}{l}\text { Tidak } \\
\text { Bagus }\end{array}$ \\
\hline
\end{tabular}

Pada tabel penilaian jitter diatas menunjukan empat divisi meliputi Graphic Design Division, Social Media Division, Public \&Meeting Room dan SEO Division mendapatkan nilai indeks 3 dengan kategori bagus. Sedangkan pada divisi Development Division mendapatkan nilai indeks 1 dengan kategori tidak bagus.
Hasil rekapitulasi penilaian kualitas jaringan pada setiap divisi Kesato Digital Agency berdasarkan standarisasi QoS dapat dilihat pada tabel berikut [17].

$$
\begin{aligned}
& \mathrm{N}=(\mathrm{Th}+\mathrm{Pl}+\mathrm{D}+\mathrm{J}) / 4 \\
& \text { Rumus: } \\
& \text { - } \quad \mathrm{N}=\text { Nilai } \\
& \text { - } \mathrm{Pl}=\text { Index Packet Lost } \quad \mid \mathrm{D}=\text { IndexDelay } \\
& \text { - } \mathbf{J}=\text { Index Jitter }
\end{aligned}
$$

Nilai QOS Graphic Design Division adalah $\mathrm{N}=(0+3+4+3) / 4=2,5$

TABEL XI

PENILAIAN QOS PADA SETIAP DIVISI

\begin{tabular}{|l|l|l|l|}
\hline No & Divisi & Nilai & Kategori \\
\hline 1 & Graphic Design Division & 2,5 & $\begin{array}{l}\text { Kurang } \\
\text { Memuaskan }\end{array}$ \\
\hline 2 & Social Media Division & 3 & Memuaskan \\
\hline 3 & Public \& Meeting Room & 3 & Memuaskan \\
\hline 4 & SEO Division & 3,25 & Memuaskan \\
\hline 5 & Development Division & 2,75 & $\begin{array}{l}\text { Kurang } \\
\text { Memuaskan }\end{array}$ \\
\hline
\end{tabular}

Menurut penilaian QoS dengan standar TIPHON menunjukan pada Graphic Design Division memperoleh nilai 2,5 dengan kategori kurang memuaskan. Pada Social Media Division memperoleh nilai 3 dengan kategori memuaskan. Kemudian Public \& Meeting Room memperoleh nilai 3 dengan kategori memuaskan. Adapun pada SEO Division juga memperoleh nilai 3,25 dengan kategori memuaskan. Selanjutnya pada Development Division memperoleh nilai 2,75 dengan kategori kurang memuaskan. Hasil ini menunjukan rata-rata penilaian QoS pada Kesato Digital Agency berada pada kategori memuaskan. Namun perlu diperhatikan hasil penilaian pada divisi Graphic Design Division dan Development Division perlu dilakukan evaluasi oleh administrator jaringan. Melihat hasil penilaian QoS pada dua divisi tersebut berada pada katergori kurang memuaskan. Pada Tabel 12 akan ditunjukan hasil rekapitulasi pengukuran parameter QoS pada setiap divisi [18]. Keterangan:

$$
\begin{array}{ll}
\text { - } & \mathrm{GDD}=\text { Graphic Design Division } \\
\text { - } & \mathrm{SMD}=\text { Social Media Division } \\
\text { - } & \mathrm{PMR}=\text { Public \& Meeting Room } \\
\text { - } & \mathrm{SEO}=\text { SEO Division } \\
\text { - } & \mathrm{DD}=\text { Development Division }
\end{array}
$$

TABEL XII

REKAPITULASI PENGUKURAN PARAMETER QOS

\begin{tabular}{|l|l|l|l|l|l|}
\hline \multirow{2}{*}{$\begin{array}{c}\text { Parameter } \\
\text { QoS }\end{array}$} & \multicolumn{5}{|c|}{ Analisis QoS Pada Divisi } \\
\cline { 2 - 6 } & GDD & SMD & PMR & SEO & DD \\
\hline Jitter & 11,43 & $\begin{array}{l}3,83 \\
\mathrm{~ms}\end{array}$ & $\begin{array}{l}2,76 \\
\mathrm{~ms}\end{array}$ & $\begin{array}{l}2,43 \\
\mathrm{~ms}\end{array}$ & $\begin{array}{l}188,2 \\
\mathrm{~ms}\end{array}$ \\
\hline
\end{tabular}




\section{REFERENSI}

\begin{tabular}{|l|l|l|l|l|l|}
\hline Packet Loss & $5 \%$ & $0,26 \%$ & $0,92 \%$ & $1,73 \%$ & $0,32 \%$ \\
\hline Delay & $\begin{array}{l}2,44 \\
\mathrm{~ms}\end{array}$ & $\begin{array}{l}2,43 \\
\mathrm{~ms}\end{array}$ & $\begin{array}{l}3,56 \\
\mathrm{~ms}\end{array}$ & $\begin{array}{l}2,43 \\
\mathrm{~ms}\end{array}$ & $\begin{array}{l}4,89 \\
\mathrm{~ms}\end{array}$ \\
\hline Throughput & $\begin{array}{l}252,085 \\
\mathrm{kbps}\end{array}$ & $\begin{array}{l}590,38 \\
\mathrm{kbps}\end{array}$ & $\begin{array}{l}619,175 \\
\mathrm{kbps}\end{array}$ & $\begin{array}{l}878,9 \\
5 \mathrm{kbps}\end{array}$ & $\begin{array}{l}504,7 \\
65 \\
\mathrm{kbps}\end{array}$ \\
\hline
\end{tabular}

Hasil rekapitulasi pengukuran dengan parameter QoS pada setiap divisi pada Kesato Digital Agency dapat dilihat pada Tabel 12 yang akan dijelaskan sebagai berikut.

a. Penilaian jitter menunjukan pada Graphic Design Division (GDD), Social Media Division (SMD), Public \& Meeting Room (PMR) dan SEO Division bernilai antara 0 hingga

75 yang artinya dalam kategori baik. Sedangkan Development Division (DD) bernilai antara 125 hingga 225 yang artinya dalam kategori tidak bagus [19].

b. Penilaian Packet Loss menunjukan Social Media Division (SMD), Public \& Meeting Room (PMR) SEO Division dan Development Division (DD) bernilai di bawah 3\% yang artinya dalam kategori sangat bagus dan Graphic Design Division (GDD) bernilai di atas 3\% yang artinya dalam kategori bagus [20].

c. Penilaian Delay menunjukan pada Graphic Design Division (GDD) bernilai 2.44, Social Media Division (SMD) bernilai 2.43, Public \& Meeting Room (PMR) bernilai 3.56, SEO Division bernilai 2.43 dan Development Design (DD) bernilai 4.89. Hasil ini menunjukan rata-rata delay $<150 \mathrm{~ms}$ sesuai standar TIPHON dalam kategori sangat bagus [21].

d. Penilaian Throughput menunjukan Development Division bernilai $504.765 \mathrm{kbps}$ dalam Social Media Division bernilai 590.38 kbps, Public \& Meeting Room bernilai 619.175 kbps kategori kurang bagus. Kemudian Graphic Design Division bernilai 252.085 kbps dalam kategori buruk. SEO Division bernilai 878.95 dalam kategori Cukup.

\section{KESIMPULAN}

Berdasarkan hasil analisis pada jaringan Komputer Kesato Digital Agency menunjukan penilaian berdasarkan parameter quality of service dalam kategori memuaskan. Untuk mendapatkan penilaian terhadap kualitas jaringan yang diterapkan pada suatu perusahaan, tentunya dapat diukur dengan qualitu of service dengan parameter throughput, delay, jitter dan packet loss dalam meningkatkan kinerja layanan jaringan. Tujuan untuk mendapatkan kualitas layanan jaringan yang baik dapat dilaksanakan dengan penilaian $Q o S$ secara rutin untuk mengevaluasi kinerja layanan jaringan yang diterapkan. Hasil evaluasi dapat memberikan gambaran pada administrator jaringan dalam upaya perbaikan untuk memberikan layanan jaringan secara adil dan merata [22]. Sehingga dapat mengatasi traffic internet yang menyebabkan jaringan menjadi lambat.
S. Jumiati, "Analisa bandwidth menggunakan metode antrian per connection queue," J. Teknol. dan Sist. Inf. Univrab, vol. 2, no. 2, pp. 1-16, 2017.

D. Kurnia, "Analisis qos pada pembagian bandwidth dengan metode layer 7 protocol, pcq, htb dan hotspot di smk swasta alwashliyah pasar senen," cess Journal Comput. Eng. Syst. Sci., vol. 2, no. 2, pp. 1-10, 2017.

P. I. S. M. Silitonga, "Analisis qos (quality of service) jaringan kampus dengan menggunakan microtic routerboard (studi kasus: fakultas ilmu komputer unika santo thomas s.u)," TIMES, vol. 3, no. 2, pp. 1-6, 2014.

[4] J. L. Putra, L. Indriyani, and Y. Angraini, "Penerapan sistem keamanan jaringan menggunakan VPN dengan metode PPTP pada pt. asri pancawarna," Indonesian J. Comput. Inf. Technol., vol. 3, no.

[5] T. Pratama, M. A. Irwansyah, and Yulianti, "Perbandingan metode PCQ, SFQ, RED dan FIFO pada mikrotik sebagai upaya optimalisasi layanan jaringan pada fakultas teknik universitas tanjungpura," J. Tek. Inform. Univ. Tanjungpura (Tommy Pratama), pp. 1-6, 2015.

[6] I. Faisal, and A. Fauzi, "Bandwith menggunakan metode queue tree dan PCQ per connection queueing," J. Teknol. dan Ilmu Komput. Prima, vol. 1, pp. 137-142, 2019.

[7] M. F. Asnawi, "Aplikasi konfigurasi mikrotik sebagai manajemen bandwidth dan internet gateway berbasis web," J. PPKM I, pp. 42$48,2018$.

[8] R. Wulandari, “Analisis QoS quality of service pada jaringan internet studi kasus upt loka uji teknik penambangan jampang kulon lipi ,"J. Tek. Inform. dan Sist. Inf., vol. 2, pp. 162-172, 2016.

[9] P. R. Utami, "Analisis perbandingan quality of service jaringan internet berbasis wireless pada layanan internet service provider ISP indihome dan first media,"J.Ilm. Teknol. dan Rekayasa., vol. 25, no. 2, pp. 125-137, 2020.

[10] L. D. D. Saputra, and W. Sulistyo, "Analisis QoS differentiated service pada jaringan mpls menggunakan algoritma threshold," $J$. Teknol. Inf. dan Ilmu Komput., vol. 4, no. 4, p. 227, 2017.

[11] Y. A. Pranata, I. Fibriani, and S. B. Utomo, "Analisis optimasi kinerja quality of service pada layanan komunikasi data menggunakan NS-2 di pt. pln persero jember," Sinergi, vol. 20, no. 2, p. 149, 2016.

[12] A. N. W. Wardhana, M. Yamin, and L. F. Aksara, "Analisis quality of service qos jaringan internet berbasis wireless lan pada layanan indihome," semanTIK, vol. 3, no. 3, pp. 201-248, 2017.

[13] I. N. Bernadus, N. Gunantara, and K. O. Saputra, "Analisis kinerja jaringan internet menggunakan metode class based queueing CBQ di universitas dhyana putra," Maj. Ilm. Teknol. Elektro., vol. 18, no. 1, pp. 133-140, 2019

[14] I. K. S. Satwika, I. M. Sukafona,"Analisis coverage dan quality of service jaringan WIFI 2,4 Ghz di stimik stikom indonesia, " Jurnal Resistor., vol. 1, no. 1, pp. 1-7, 2018.

[15] M. Purwahid, J. Triloka, "Analisis quality of service QOS jaringan internet untuk mendukung rencana strategis infrastruktur jaringan komputer di SMK N 1 sukadana, "JTKSI., vol. 2, no. 3, pp. 100-109, 2019.

[16] Mardianto, "Analisis quality of service QOS pada jaringan VPN dan MPLS VPN menggunakan GNS3," Jurnal Sains dan Informatika., vol. 5, no. 2, pp. 98-107, 2019.

[17] M. Siddik, "Analisis quality of service jaringan local area network menggunakan mikrotik routerboard750 studi kasus stimik royal kisaran," Jurteksi., vol. 5, no. 2, pp. 113-118, 2019.

[18] S. W. Pamungkas, Kusrini, and E. Pramono, "Analisis quality of service QoS pada jaringan hotspot SMA negeri xyz, "Jurnal Sistem Informasi dan Teknologi Informasi., vol. 7, no. 2, pp. 142-152, 2018.

[19] R. Kango, I. Ibrahim, "Analisis quality of service aplikasi voice over internet protocal pada jaringan mobile adhoc network, "Jurnal Sains Informasi Geografi., vol. 1, no. 2, pp. 21-27, 2018.

[20] R. Nindyasari, A. C. Murti, and M. I. Ghozali, "Analisis QoS quality of service jaringan UNBK dengan menggunakan microtic router studi kasus jaringan UNBK SMA N 1 jakenan pati, "Jurnal Ilmiah NERO., vol. 4, no. 2, pp. 109-116, 2019. 2, pp. 260-267, 2018. 
[21] W. Y. Pusvita, Y. Huda, "Analisis kualitas layanan jaringan internet WIFI ID menggunakan parameter QoS quality of service, "Voteknika., vol. 7, no. 1, pp. 54-60, 2019.

[22] I. G. A. Y. Utama, I. G. N. A. J. Sasmita, and L. Jasa, "Manajemen jaringan internet di dinas kesehatan provinsi bali dengan menggunakan hierarchical token bucket, " Maj. Ilm. Teknol. Elektro., vol 19, no. 2, pp. 163-170, 2020. 